to reduce patient distress, risks to the public and long-term costs to the criminal justice and healthcare systems.

Nevertheless, we have concerns regarding the proposal that the diagnostic process and case formulation be undertaken wholly by offender managers along with forensic and clinical psychologists. ${ }^{1}$ Although we value the important contribution from our colleagues in the ongoing management of this group of patients, it is more appropriate that the diagnosis should be carried out by medically qualified doctors, i.e. psychiatrists.

Those who have experience in forensic psychiatric settings appreciate that mentally ill offenders present with complex psychopathologies. The diagnosis and case formulation including management pathways require the corresponding level of experience, training and skill, particularly given the mandatory nature of this patient group's detention. A percentage of offenders who appear to present with functional mental disorders will in fact be presenting with endocrine, neurological, immunological or other related conditions. This requires medical training to identify. A 'diagnostic questionnaire' would be too simplistic, too inaccurate and would potentially lend itself to an underdiagnosis of personality disorder. In addition, if questionnaires and criteria for diagnosis are employed based on the face value, the error then would be an overdiagnosis of personality disorder. This would result in attaching a 'personality disorder' label to a selected group of patients. These patients are known to be stigmatised by society and at times excluded from prison treatment programmes, or worst still, marginalised by healthcare services. The presumptive diagnosis often significantly influences the latter stages of a patient's care pathway. This includes its direction (criminal justice or healthcare), sentencing, custody and the necessary level of health service input at each subsequent stage. A diagnosis achieved by a psychiatrist, whose training as a medical doctor requires years of experience, would surely be better than having significant numbers of patients being inaccurately categorised based on a form.

The skill of the medical doctor is in evaluating the patient as a whole, considering the symptoms and signs while utilising the appropriate diagnostic tools based on current evidence or guidelines. Having achieved a diagnosis, the real utility of a medical doctor is in treating the patient. Knowledge and experience in all medical conditions are therefore essential. This is important for a patient group with very serious psychiatric comorbidities such as psychosis, mood disorders and paraphilias. ${ }^{3}$ It is accepted that at present treatment regimes for personality disorder are largely psychosocial in nature. However, correct treatment starts with correct diagnosis. In our experience, high psychiatric and physical comorbidities often necessitate the use of medication. Medical treatments for personality disorder and its manifestations (such as emotional lability and aggression) are increasingly being recommended as the evidence base supporting their efficacy expands. ${ }^{4,5}$ The treatment of these symptoms is pertinent in contributing to the patient's risk reduction and hence future reoffending. The psychiatrist, apart from prescribing physical treatments and having a more holistic view, is able to discuss and refer the patient to other medical and surgical specialties if the need arises. The importance of such medical discussion and conference should not be underestimated, particularly if it relates to aetiology, as a missed or inaccurate diagnosis at the onset would result in repeated assessments conducted at various junctures and with added costs, longer waiting times and escalation of risks.

In our view, a thorough initial diagnosis and case formulation of personality disordered offenders by a psychiatrist is the crucial starting point. Providing the diagnostic expertise deserved by this complex patient group from the earliest stage ensures value for money for the taxpayer, a more accurate risk formulation and, most importantly, a fair and clinically based service for a very vulnerable and stigmatised group of people in our society.

1 Department of Health, Ministry of Justice. Consultation on the Offender Personality Disorder Pathway Implementation Plan. TSO (The Stationery Office) (http://www.dh.gov.uk/prod_consum_dh/groups/ dh_digitalassets/documents/digitalasset/dh_124489.pdf).

2 Duggan C. Dangerous and severe personality disorder. Br J Psychiatry 2011; 198: 431-3.

3 Coid J. The co-morbidity of personality disorder and lifetime clinical syndromes in dangerous offenders. J Forensic Psychiatry Psychol 2003; 14: $341-66$.

4 Nose M, Cipriani A, Biancosino B, Grassi L, Barbui C. Efficacy of pharmacotherapy against core traits of borderline personality disorder: meta-analysis of randomized controlled trials. Int Clin Psychopharmacology 2006; 21: 345-53.

5 Ingenhoven $\mathrm{T}$, Lafay $\mathrm{P}$, Rinne $\mathrm{T}$, Passchier J, Duivenvoorden $\mathrm{H}$. Effectiveness of pharmacotherapy for severe personality disorders: meta-analyses of randomized controlled trials. J Clin Psychiatry 2010; 71: $14-25$.

Dumindu Witharana is a specialist registrar, Personality Disorder Unit, Broadmoor Hospital, Crowthorne, UK, email: duminduwitharana@nhs.net; David K. Ho, specialist registrar, Fintan Larkin, consultant forensic psychiatrist, both also at Broadmoor Hospital.

doi: $10.1192 /$ pb.35.9.355a

\section{Prison GP services are reluctant to prescribe psychotropics}

The significant frustration felt by those routinely working in the difficult and challenging environment of prison has rightly had the spotlight shone upon it. ${ }^{1}$ In my experience, general practitioners (GPs) working in these settings are reluctant to prescribe psychotropic medications, often to the point of obstinacy.

The reasons put forward are mostly that: (a) the GPs themselves have no experience or confidence in prescribing these medications, and (b) there is a perception that this is solely the remit of in-reach mental health services. The second explanation has taken on absurd dimensions where prison GPs have refused to continue a prescription of a commonly used antidepressant, started by a GP in the community, without it being authorised by a psychiatrist!

I would like to see a similar study done comparing the continuity of prescribing of other chronic medications (i.e. antihypertensives or antihyperglycaemic agents) for newly received prisoners. I suspect that there would be significantly less discontinuity with these agents, as a GP would be rightly criticised for claiming that he or she would not continue with a patient's angiotensin-converting enzyme (ACE) inhibitor unless it was prescribed by a cardiologist! Indeed, a recent audit from the Offender Health Research Network ${ }^{2}$ hinted that psychotropic medications were more likely to be omitted 
following reception than other medications. In my view, this issue highlights the ongoing fault lines of professional disdain and mistrust towards psychiatry among our other medical colleagues. $^{3-5}$ Solving this problem will have to go beyond the platitude of the 'additional training required' and will necessitate a significant drive to improve the image of psychiatry as a credible medical discipline.

1 Hassan L, Senior J, Edge D, Shaw J. Continuity of supply of psychiatric medicines for newly received prisoners. Psychiatrist 2011; 35: 244-8.

2 Offender Health Research Network. An Audit of Medication Prescribing Practices following Imprisonment. OHRN, 2010 (www.ohrn.nhs.uk/ resource/Research/MedicationAuditOHRN2010.pdf).

3 Craddock N, Antebi D, Attenburrow MJ, Bailey A, Carson A, Cowen P, et al. Wake-up call for British psychiatry. Br J Psychiatry 2008; 193: 6-9.

4 Brockington IF, Mumford DB. Recruitment into psychiatry. Br J Psychiatry 2002; 180: 307-12

5 Storer D. Recruiting and retaining psychiatrists. Br J Psychiatry 2002; 180: $296-7$

Trevor D. Broughton, consultant forensic psychiatrist, Norwich, UK, email: trevor.broughton@nwmhp.nhs.uk

doi: $10.1192 / p b .35 .9 .356$

\section{Emotional doctors in the house!}

Stanton et al have produced a thought-provoking study on emotional intelligence, and, in a selfless move which I hope will add to their findings that psychiatrists score highly on social responsibility scale, I would like to correct their assertion that Sir Lancelot Spratt was a product of the Carry On films. He was in fact a recurring terror in the Doctor in the House series.

1 Stanton C, Sethi FN, Dale O, Phelan M, Laban JT, Eliahoo J. Comparison of emotional intelligence between psychiatrists and surgeons. Psychiatrist 2011; 35: 124-9.

Mike Smith, Senior Psychiatric Registrar, Canterbury District Health Board, Christchurch, New Zealand, email: michael.smith@cdhb.govt.nz doi: $10.1192 /$ pb.35.9.357

\section{Change for better or worse - New Ways of Working?}

The factors psychiatrists feel induce and relieve stress in the course of their working lives, as presented in the paper by Rathod et al, are interesting and thought provoking. In our opinion, however, the findings are interpreted idiosyncratically, just possibly influenced by the first author's role as consultant in a crisis resolution and home treatment team.

The authors highlighted the finding that functional teams were rated as reducing psychiatrists' stress levels, applauding the positive effects of National Health Service (NHS) changes. Whereas consultants reported stress as a result of working across interfaces and from loss of continuity of care, Rathod et al write: 'It is the authors' opinion that it is the consequences of these changes... that are causing the stress rather than the changes per se'. So the changes are good, it is just their consequences that are bad? In fact, $21.4 \%$ of consultants in the study listed the creation of functional teams as stress reducing, whereas $49 \%$ and $44 \%$ respectively cited working across interfaces and loss of continuity of care as factors that caused stress.

New Ways of Working was introduced principally with the aim of reducing stress among psychiatrists. The possibility that the resultant loss of continuity of care, bemoaned both by patients $^{2}$ and by psychiatrists ${ }^{3}$ for its negative clinical effects, may have actually increased psychiatrists' stress levels does seem to be a most unfortunate outcome.

The counterbalance to stress in most areas of work is that of job satisfaction, a point that Rathod et al do not address. Especially at a time when recruitment into our specialty is falling, the point is an important one. For many practising psychiatrists, it is the continuity of responsibility for our case-loads of patients that provides job satisfaction and moderates stress.

If service changes have been associated with increased stress among psychiatrists and with reduced patient satisfaction, both against a backdrop of a crisis in recruiting doctors into psychiatry, is it perhaps time to think again?

1 Rathod S, Mistry M, Ibbotson B, Kingdon D. Stress in psychiatrists: coping with a decade of rapid change. Psychiatrist 2011; 35: 130-4.

2 Singhal A, Garg D, Rana AK, Naheed M. Two consultants for one patient: service users' and service providers' views on 'New Ways'. Psychiatrist 2010; 34: 181-6.

3 Dale J, Milner G. New Ways not working? Psychiatrists' attitudes. Psychiatr Bull 2009; 33: 204-7.

John M. Eagles, consultant psychiatrist, Royal Cornhill Hospital, Aberdeen, UK, email: john.eagles@nhs.net; Mugdha Kulkarni, CT 1 psychiatry, Royal Cornhill Hospital, Aberdeen.

doi: 10.1192/pb.35.9.357a

\section{Sexual Offences Act - issues where both individuals lack capacity}

Psychiatrists, especially those working with people with intellectual disabilities, may encounter situations where two individuals who engage in sexual contact both lack capacity. It may be that the contact is consensual, but it could be argued that the individuals are committing an offence, as both parties lack capacity. However, to construe the act as an offence would be tantamount to asserting that individuals lacking capacity should not engage in sexual contact, and this could be seen as an infringement of their human rights.

There is no simple answer to such a situation. The sexual contact might be grounds for initiating safeguarding procedures if there is a power imbalance between the concerned persons. Where the act is consensual, clinicians are faced with a dilemma and need to balance the patients' autonomy and rights against their professional duty of care to protect patients. A best interests meeting might help to resolve the issues and arrive at a consensus of opinion.

Prabhat Mahapatra is a consultant psychiatrist, South West Yorkshire Partnership Foundation NHS Trust, Wakefield, UK, email: prabhat.mahapatra@nhs.net, Pravati Mishra is a trust grade doctor, South West Yorkshire Partnership Foundation NHS Trust, Wakefield. doi: 10.1192/pb.35.9.357b

\section{Who should manage metabolic dysregulation?}

Bainbridge et al's paper ${ }^{1}$ on general practitioners' (GPs') attitudes on who should manage metabolic dysregulation associated with antipsychotics is interesting, topical and important, although we would like to make a couple of comments. 